\title{
Efficacy of Group Reality Therapy on Anxiety in Infertile Women Undergoing Treatment with Assisted Reproductive Techniques IUI
}

\author{
Habibeh SoltanzadehMezreji \\ M. A.in general psychology, Department of Psychology, School of Humanities, Torbatjam Branch, \\ Islamic Azad University, Iran
}

\section{Hassan Toozandehjani}

Assistant Professor, Ph. D. of Psychology, Department of Psychology, School of Humanities, Nishapur Branch, Islamic Azad University, Nishapur, Iran

\author{
Doi:10.5901/mjss.2016.v7n3s3p127
}

\begin{abstract}
Infertility is a complex crisis in the lives of infertile couples and a source for anxiety in these individuals. Reaction to infertility by negative psychological reactions including incompetent individual, marital and relationship problems and disorders, is observed. The present study examined the efficacy of group reality therapy on in infertile women undergoing treatment with assisted reproductive techniques (IUI) in Mashhad. For this purpose, of infertile women attending NOVIN infertility clinic in Mashhad to treat Intrauterine Insemination (IUI), 60 subjects volunteered by the SpielbergerAnxiety Inventory were evaluated. Then 40 patients by simple random selected and randomly divided into two experimental $(n=20)$ and control $(n=20)$ groups. Group reality therapy in the experimental group were administered over 10 sessions 1 and half hour. The control group received no intervention. Both groups after treatment and before IUI, were tested again. The results of the statistical parameters (such as t-independent group, covariance analysis) were analyzed. Findings showed, the group reality therapy interventions to reduce anxiety within the experimental group significantly $(p<0.05)$ has been effective. Given the positive effects of group reality therapy on anxiety in infertile women undergoing treatment with assisted reproductive techniques IUI, this approach to reduce the psychological disorders and improve quality of life for this group of women is recommended.
\end{abstract}

Keywords: Infertility, reality therapy, anxiety.

\section{Introduction}

Infertility is defined as not having a child after one year of regular intercourse without using any contraceptive method (Mohammadi\&Khalajabadi, 2000). According to available statistics, 10-15 percent of couples in infertility age have a reproduction problem (Heydari et al., 2002). Infertility is one of the most important life crises which causes anxiety experiencesand mental health problems for people (Sadock, Kaplan\&Sadock). Inability to have a baby can be a huge stress for one or both of the spouses. Response to Infertility is associated with severe negative reactions. Severe negative reactions can be seen in infertile couples such as grief, denial, sexual and personal incompetence, threat to selfesteem, marital distress, and problems in relationships with others (Farahani, 2001).

Infertility is a process that influencesthe body, occupation, personality and mind of an individual and has hedonic adverse effects on his/her emotions (Faal, Kalkguran et al.). Impulsive behavior, scattered anger and frustration, especially in long-term and sometimes unsuccessful treatments, negative beliefs about yourself, feelings of rejection and difficulty in sexual relationship and many other psychological problems are among those that researchers have been reported about infertile individuals. Even though both spouses experience the crisis, however, studies suggest that women experience more negative psychological effects compared to men. One of the reasons that cause psychological pressure for infertile women is the role of motherhood which in most societies is considered as the most important role of women in adulthood. As a result, infertile women are facing more stress. Moreover, since many of tests and treatments of infertility are performed on women, it will only increase the psychological pressure and all the factors cause infertile women to consider themselves responsible for infertility (Farahani 2001,FaalKalkguran et al. 2011,Gibson \& Myers, 2000). Domar et al. 2000, (quoted by Khodakarami et al., 2006)found that half of infertile patients show a change in sexual relationship and 75 percent of them show changes in mood states.

In a research by Behdani et al., (2005) to assess the general health of infertile women that were performed on 963 
infertile women, it was found that the most common psychological disorder in infertile women is the generalized anxiety disorder. Vijeh 2005 (quoted from Khodakarami et al.,2006) in qualitative studies on infertile urban women in India showed that women are deeply concerned about their position and security being affected by infertility and they experience loneliness. Furthermore the process of using assisted reproductive technology due to physiological, emotional and financial pressureswas very stressful for thembecause infertility is a shameful phenomenon in Indian society.

Treatment of infertility depends on the type of disorder of the couples. If couples treatment is not performed using common medical and surgical procedures andit cannot be treated by conventional methods, new techniques of infertility treatment namely Assisted ReproductiveTechniques must be utilized.One of these methods is Intrauterine Insemination (IUI). One of the oldest methods of infertility treatment is a method in which a man's sperm after preparation is transferred to the uterus that includes a variety of ways in which the sperm enters the different parts of female reproductive tract. The aim of this action is to provide a greater number of sperm in the uterus. Intrauterine insemination (IUI) is of most common and known types of artificial insemination and it is common in different cases of infertility treatment. Patients undergoing assisted reproductive techniques are often concerned about their medical program's failure (9).

Cognitive-behavioral therapy as methods of coping with psychological problems during medical treatments has been proposed by many researchers. Tuscan et al.,1999(quoted by Chubforoshzadeh et al.) by establishing a six-month cognitive-behavioral therapy program for infertile couples achievedresults including an increase in sperm density, decrease in hopeless thoughts, and a decrease in marital dissatisfaction.

Ellen et al. (2002) conducteda research on infertile couples to determine the effectiveness of brief psychological supports and anxiety control during treatment with InteraVitero Fertilization method. The results showed that women who participated in the group meetings (compared to the control group) showed less anxiety after IVF, however, the men who participated in the meetings (compared to the control group or those women who were undertreatment) were more optimistic and confirmed many of their irrational beliefs. Studies byTerzioglu (2001) and Newton et al. (1992) on the effect of psychological and psychiatric interventions on mental disorders in infertile couples showed that psychological interventions lead to reduction of anxiety and depression in them.

Research by Chubfrushzadeh, Kalantari and Molavi (Ellen et al. 2002) which conducted with aim to investigate the effects of cognitive-behavioral stress management therapy on quality of life in infertile women, indicated the effectiveness of the treatment on quality improvement of life in infertile women. The results of the study by Heidari et al. (2002) showed that CBT interventions reduce anxiety in infertile women undergoing IUI treatment. Results of this study by Hamid (2010) on the effectiveness of stress management on anxiety in infertile women showed that anxiety in the experimental group compared to the control group in the post-test stage had a significantreduction. The findings by Seddiqi et al. (2004) showed that initial preparation for reducing anxiety in pre-treatment programs of infertile women and increasing their fertility is effective.

Since the facts are sustainable affairs, existential theorists and Glaser believe thatfact understanding is based on the perception and structure of the human personality and depends on his interpretation of the reality (Shovakazemi\&JafariHarandi 2009). Glasser believes that all human behaviors are to satisfy basic physiological and psychological needs which exist in all human beings. Sometimes In distinction between reality and non-reality, he/she denies a part or all of it and thus we refer tothem as patients. Those who are unable to meet their basic needs, require psychotherapy. People who lack love and worthiness or are involved in some kind of failure and deficiencyshow symptoms such as aggression, depression and jealousy (Navabinzadeh, 2008).

Applying group reality therapy is based on a collection of research findings that show the individual in the light of a series of group motivational effects, undergoes changes in him/herself. Group activities while make people aware of the previously unknownproblems, they cause relief and serenity in the individual, because he/she comes to the conclusion that others also have similar problems (Navabinzadeh, 2008). Reality therapy will be effective when the patient is able to leave aside the denial of the world and realizes that not only the reality is there, but also he can only satisfy his/her needs in its framework. Reality therapy has a different way of working with people. Tools of reality therapy include intense emotional relationship of the individual, facing with the facts, abandoning the irresponsible behavior and training of better behavior style (Glaser, 2006).

Prenzlau (2006) investigated the effectiveness of reality therapyinterventions (based on choice theory) on patients with post-traumatic stress disorder, (PTSD). The results showed that these interventions is effective in reducing thought rumination. Loyd(2005) studied the effect ofreality therapy on feeling of satisfaction of needs and behavior change in high school students. The results showed that teachingreality therapy principles to students helps them to meet needs such as fun, freedom and power. Kym (2008) in a study conducted on patients with schizophrenia came to the conclusion that reality therapy causes positive changes in the components of internal control, self-esteem and coping with stress. Peterson, Collins \& Chang (1998) surveyed the effect of training of choice theory or reality therapygroup counseling in 
creating and sustaining a positive self-concept in Taiwanese students. The results showed that both strategies are effective in increasing positive self-concept.

Pasha and Amini (2008) investigated the effectiveness of thereality therapy on anxiety and life expectancy in wives of martyrs. The results showed that the reality therapy decreases the anxiety and increases life expectancy of the wives. A Research by Qaffari, QanbariHashemabadi and AqamohamadianSherbaf (2008) to compare the group efficacy based on choice theory and systematic motivational therapy to increase marital satisfaction showed that both treatment methods lead in marital satisfaction. Farahbakhsh and QanbariHashemabadi (2006) studied the effectiveness of couples therapy based on Glaser reality therapy on the post-traumatic stress disorder patients after awareness of marital infidelity and also increase in their intimate relationships. They found that interventions such as establishing an emotional connection, encouraging couples to judge and assess their behavior in interaction with spouse could reduce psychological problems and stress caused by marital infidelity and increase inthe love and intimate relationships of couples.

The results of a research by Moradi, QanbariHashemabadi and AqamohamadianSherbaf (2006) on the effectiveness of group reality therapy in students increased self-esteem indicates the effectiveness of group reality therapy in increased self-esteem of the students in the experimental group. The results of a research by Aqayi (2008) showed a positive effect of reality therapy in increasing the hope and mental health of infertile women with donated eggs. Mashayekhi (2008) also reported the effect of group reality therapyon reducing solitude feeling in women.Poormohseni(2009) confirmed the effectiveness ofGlaser marital empowerment programs on marital satisfaction. Shafiabadi, Hoseinpoor et al. (2009) reported the efficacy of education in reality therapy form on reducing the anxiety of female students. According to the aforementioned studies, the main question of this study is whether the interventions of reality therapy could influence the anxiety in infertile women undergoing treatment with IUI assisted reproductive techniques?

\section{Methods}

The population of this study included 60 infertile women subjects whocame to Mashhad Novin Infertility Center to be treated by IUI. From the 60 infertile women,then 40 patients by simple random selected and randomly divided into two experimental $(n=20)$ and control $(n=20)$ groups. The study was semi-experimental with pretest-posttest along with control group. Group reality therapy in the experimental group were administered over 10 sessions 1 and half hour. The control group received no intervention. Both groups after group reality therapy intervention in posttest stage and before IUlin pretest stage, were evaluatedby the Spielberger State-Trait Anxiety Inventory.

\subsection{Research Tools}

\subsubsection{State-Trait Anxietyinventory}

The self-report questionnaire has been developed by Spielberger(1970). In this study, a translated version by Mahram (1372) is used. This test consists of 40 phrases and measures the anxiety characteristics in either "state" or "trait" mode. State anxiety scale reliability was 0.91 and trait anxiety scale reliability was obtained 0.90 . For the entire test, reliability is achieved 0.94 (Mahram 1993). In order to study validity, concurrent validity method was used which according to the study in both state and trait anxiety scales and also the entire test, a significant differences in levels of 0.01 and 0.05 between norm and criterion group has been obtained based on the mean values (Behdani et al., 2000). In addition, the reliability of the test is calculated based on the ratio of the actual variance to the observed variance and the rate in the normal group was reported 0.95 . The standard error of measurement was equal to 4.64. Moreover, the observed scores correlation with the actual score was equal to 0.97 and with error scores was equal to 0.23 , respectively (33).

\subsection{Methods of data analysis}

In order to analyze the data, t-test was used in independent groups (for comparing the mean scores of the two groups), and analysis of covariance was performed using spss software.

Reality therapy sessions were held as follows:

- First session: implementation of the pre-test and diagnostic interview.

- Second session: familiarity of members with the concept ofreality therapy and emotional interaction with group members.

- Third session: members' familiarization with their own identity, the types of identity and characteristics of a 
successful identity and the identity of defeat.

- Fourth session:members' familiarization with how to take responsibility for their behavior and importance and necessity of responsibility in life.

- Fifth Session: Introduction to anxiety from the perspective ofreality therapy and anxiety management skills training.

- Sixth Session: members' familiarization with basic and effective needs in real life, the effect of the need for life and their ability to choose the best way to achieve these requirements.

- Seventh session:members' familiarization with how to plan problem solving, planning for their current life and for preparedness for the treatment assisted reproductive method IUI.

- Eighth Session: members' familiarization with the commitmentto implementation ofcarried-out and medical programs.

- Ninth Session: members' familiarization with denying excuses on the implementation of selected projects and programs.

- Tenth session: execution of the post-test

\section{Findings}

Table 1. Mean pretest and posttest scores of Spielberger State-Trait Anxiety inventory

\begin{tabular}{|c|c|c|c|c|c|c|c|c|}
\hline & & & No. & Min & $\operatorname{Max}$ & Average & Standard deviation & Coefficient of skewness \\
\hline \multirow{4}{*}{ Control group } & \multirow{2}{*}{ State anxiety } & Pretest & 20 & 22 & 72 & $52 / 95$ & $12 / 12$ & $0 / 85$ \\
\hline & & Posttest & 20 & 23 & 65 & $49 / 95$ & $11 / 237$ & $0 / 482$ \\
\hline & \multirow{2}{*}{ Trait anxiety } & Pretest & 20 & 22 & 79 & $55 / 45$ & $12 / 5$ & $0 / 934$ \\
\hline & & Posttest & 20 & 21 & 73 & $52 / 35$ & 11/97 & $0 / 842$ \\
\hline \multirow{4}{*}{ Experimental group } & \multirow{2}{*}{ State anxiety } & pretest & 20 & 26 & 83 & $50 / 3$ & $14 / 76$ & $0 / 215$ \\
\hline & & Posttest & 20 & 25 & 55 & $37 / 35$ & $8 / 015$ & $0 / 51$ \\
\hline & \multirow{2}{*}{ Trait anxiety } & pretest & 20 & 24 & 69 & $49 / 65$ & $12 / 86$ & 0/494 \\
\hline & & Posttest & 20 & 22 & 55 & $37 / 35$ & $7 / 95$ & 0/064 \\
\hline
\end{tabular}

Table 2. Kolmogorov-Smirnov test for investigating the normality of observations of Spielberger State-Trait Anxiety inventory in control group

\begin{tabular}{|c|c|c|c|c|}
\hline \multicolumn{2}{|c|}{ Trait anxiety } & \multicolumn{2}{c|}{ State anxiety } & \\
\hline Posttest & Pretest & Posttest & Pretest & \\
\hline $0 / 676$ & $0 / 649$ & $0 / 562$ & $0 / 856$ & Z statistic of Kolmogorov-Smirnov test \\
\hline $0 / 751$ & $0 / 793$ & $0 / 911$ & $0 / 456$ & p-value \\
\hline
\end{tabular}

Table 3. Kolmogorov-Smirnov test for investigating the normality of observations of Spielberger State-Trait Anxiety inventory in experimental group

\begin{tabular}{|c|c|c|c|c|}
\hline \multicolumn{2}{|c|}{ Trait anxiety } & \multicolumn{2}{c|}{ State anxiety } & \\
\hline Posttest & Pretest & Posttest & Pretest & \\
\hline $0 / 592$ & $0 / 623$ & $0 / 585$ & $0 / 607$ & Z statistics of Kolmogorov-Smirnov test \\
\hline $0 / 874$ & $0 / 833$ & $0 / 883$ & $0 / 855$ & p-value \\
\hline
\end{tabular}

The findings of the above tables suggest that the circumstantial evidence of Kolmogrov-Smearnov test is less than the equivalent circumstantial evidence in the standard table; therefore, there is no reason to reject the null hypothesis. In other words, in the last line of the table, $p$-value is more than 0.05 ; therefore, the null hypothesis in the mentioned tests, which says that the findings in both control and experimental groups are normal, is accepted. 
Table 4. The summary of t-test results for pretest scores of Spielberger State-Trait Anxiety inventory between the two groups

\begin{tabular}{|c|c|c|c|c|c|c|c|}
\hline \multirow{3}{*}{$\begin{array}{l}\text { The second hypothesis } \\
\text { State Anxiety }\end{array}$} & \multicolumn{2}{|c|}{$\begin{array}{l}\text { Levene test for equality of } \\
\text { variance test }\end{array}$} & & & \multicolumn{3}{|c|}{ T-test for equality of means test } \\
\hline & \multirow[t]{2}{*}{ F statistics } & \multirow[t]{2}{*}{$p$-value } & \multirow[t]{2}{*}{ statistics } & \multirow{2}{*}{$\begin{array}{l}\text { Degree of } \\
\text { freedom }\end{array}$} & \multirow[t]{2}{*}{$p$-value } & \multicolumn{2}{|c|}{$\begin{array}{l}\text { 95\% confidence interval for the } \\
\text { difference }\end{array}$} \\
\hline & & & & & & Low limit & High limit \\
\hline $\begin{array}{l}\text { Reception of equal variance } \\
\text { hypothesis }\end{array}$ & \multirow{2}{*}{ 1/953 } & \multirow{2}{*}{ 0/17 } & 0/62 & 38 & $0 / 539$ & $-5 / 99$ & $11 / 29$ \\
\hline $\begin{array}{l}\text { Rejection of equal variance } \\
\text { hypothesis }\end{array}$ & & & $0 / 62$ & $36 / 613$ & 0/539 & $-6 / 007$ & $11 / 307$ \\
\hline
\end{tabular}

The results of this table suggest that the hypothesis of the equality of the variances is not rejected based on the circumstantial evidence of the Levene test; in other words, the value of Fisher circumstantial evidence $(F) .95,1$, and $38=1.953)$ is less than its equivalent amount in Fisher table ( $F 0.95,1$, and 38=4.98). Therefore, the hypothesis of the equality of the variances in both samples is accepted. Since the amount of the absolute value of the calculated circumstantial evidence of $t(t=0.62)$ is less than its equivalent amount in the standard $t$ table $(t=1.98)$, it is concluded with the certainty of 95 percent that there is no significant difference between the control and experimental groups in pre-test which shows the homogeneity of the mentioned groups before the treatment period.

Table 5. The summary of t-test results for posttest scores of Spielberger State Anxiety inventory between the two groups

\begin{tabular}{|c|c|c|c|c|c|c|c|}
\hline \multirow{3}{*}{$\begin{array}{l}\text { The second hypothesis } \\
\text { State Anxiety }\end{array}$} & \multicolumn{2}{|c|}{$\begin{array}{c}\text { Levene test for equality of } \\
\text { variance test }\end{array}$} & & & \multicolumn{3}{|c|}{ T-test for equality of means test } \\
\hline & \multirow[t]{2}{*}{ F statistics } & \multirow[t]{2}{*}{$p$-value } & \multirow{2}{*}{$\begin{array}{c}\mathrm{t} \\
\text { statistics }\end{array}$} & \multirow{2}{*}{$\begin{array}{l}\text { Degree of } \\
\text { freedom }\end{array}$} & \multirow[t]{2}{*}{$p$-value } & \multicolumn{2}{|c|}{$\begin{array}{c}95 \% \text { confidence interval for the } \\
\text { difference }\end{array}$} \\
\hline & & & & & & Low limit & High limit \\
\hline $\begin{array}{l}\text { Reception of equal variance } \\
\text { hypothesis }\end{array}$ & \multirow{2}{*}{$1 / 594$} & \multirow{2}{*}{$0 / 214$} & $5 / 45$ & 38 & $0 / 00$ & $11 / 37$ & $24 / 82$ \\
\hline $\begin{array}{l}\text { Rejection of equal variance } \\
\text { hypothesis }\end{array}$ & & & $5 / 45$ & $32 / 363$ & $0 / 00$ & $11 / 34$ & $24 / 86$ \\
\hline
\end{tabular}

The results of this table suggest that the hypothesis of the equality of the variances is accepted based on the circumstantial evidence of the Levene test. Since the amount of the absolute value of the calculated circumstantial evidence of $t(t=5.45)$ is more than the standard $t(t=15.98)$, it is concluded with the certainty of 95 percent that there is a significant difference in the post-test scores of control and experimental groups for state anxiety test. In fact, "reality therapy had been effective in decreasing the state anxiety of infertile women."

Table 6. The summary of t-test results for pretest scores of Spielberger Trait Anxiety inventory between the two groups

\begin{tabular}{|c|c|c|c|c|c|c|c|}
\hline \multirow{3}{*}{$\begin{array}{l}\text { The second hypothesis } \\
\text { Trait Anxiety }\end{array}$} & \multicolumn{2}{|c|}{$\begin{array}{l}\text { Levene test for equality of } \\
\text { variance test }\end{array}$} & & & \multicolumn{3}{|c|}{ T-test for equality of means test } \\
\hline & \multirow[t]{2}{*}{ F statistics } & \multirow[t]{2}{*}{$p$-value } & \multirow{2}{*}{$\begin{array}{c}\mathrm{t} \\
\text { statistics }\end{array}$} & \multirow{2}{*}{$\begin{array}{l}\text { Degree of } \\
\text { freedom }\end{array}$} & \multirow[t]{2}{*}{$p$-value } & \multicolumn{2}{|c|}{$\begin{array}{l}\text { 95\% confidence interval for the } \\
\text { difference }\end{array}$} \\
\hline & & & & & & Low limit & High limit \\
\hline $\begin{array}{l}\text { Reception of equal variance } \\
\text { hypothesis }\end{array}$ & \multirow{2}{*}{$1 / 254$} & \multirow{2}{*}{$0 / 27$} & 0/079 & 38 & 0/938 & $-7 / 731$ & 8/031 \\
\hline $\begin{array}{l}\text { Rejection of equal variance } \\
\text { hypothesis }\end{array}$ & & & 0/079 & $37 / 32$ & 0/938 & $-7 / 435$ & 8/035 \\
\hline
\end{tabular}

The amount of the absolute value of the calculated circumstantial evidence of $t(t=0.079)$ is less than the standard $t$; therefore, it is concluded that there is no significant difference between the variables under investigation which shows that groups before the treatment period were homogenous. 
Table 7. The summary of t-test results for pretest scores of Spielberger Trait Anxiety inventory between the two groups

\begin{tabular}{|c|c|c|c|c|c|c|c|}
\hline \multirow{3}{*}{$\begin{array}{l}\text { The second hypothesis } \\
\text { Trait Anxiety }\end{array}$} & \multicolumn{2}{|c|}{$\begin{array}{c}\text { Levene test for equality of } \\
\text { variance test }\end{array}$} & & & \multicolumn{3}{|c|}{ T-test for equality of means test } \\
\hline & \multirow[t]{2}{*}{ F statistics } & \multirow[t]{2}{*}{ p-value } & \multirow{2}{*}{$\begin{array}{c}\mathrm{t} \\
\text { statistics }\end{array}$} & \multirow{2}{*}{$\begin{array}{l}\text { Degree of } \\
\text { freedom }\end{array}$} & \multirow[t]{2}{*}{$\mathrm{p}$-value } & \multicolumn{2}{|c|}{$\begin{array}{l}\text { 95\% confidence interval for the } \\
\text { difference }\end{array}$} \\
\hline & & & & & & Low limit & High limit \\
\hline $\begin{array}{l}\text { Reception of equal variance } \\
\text { hypothesis }\end{array}$ & \multirow{2}{*}{$1 / 912$} & \multirow{2}{*}{$0 / 175$} & $4 / 667$ & 38 & $0 / 000$ & $8 / 949$ & $21 / 506$ \\
\hline $\begin{array}{l}\text { Rejection of equal variance } \\
\text { hypothesis }\end{array}$ & & & $4 / 667$ & $33 / 045$ & 0/000 & $8 / 462$ & $21 / 538$ \\
\hline
\end{tabular}

The amount of the absolute value of the calculated circumstantial evidence of $t(t=4.667)$ is more than the standard $t$ $(\mathrm{t}=1.985)$; therefore, it is concluded with the certainty of 95 percent that there is a significant difference in the post-test scores of control and experimental groups for trait anxiety inventory. In other words, the results suggest that the researcher's hypothesis, being based on the fact that "group reality therapy is effective in decreasing the trait anxiety of infertile women under the treatment with the IUI assisted reproductive method, is accepted.

\section{Discussion}

This study aimed at investigating the effectiveness of reality therapy in decreasing the anxiety in infertile women under the treatment with the IUI assisted reproductive method. The obtained data for state anxiety and trait anxiety of infertile women suggest that the intervention of reality therapy in decreasing the state and trait anxiety of infertile women has been effective. The results of this study are in harmony with the findings of Domar (34), Terzioglu (12), Newton et al. (13), and Matthew page (35) which are based on the fact that the psychology and reality therapy intervening factors decrease the anxiety of infertile women.

The findings of the study by Heydari et al. (2) suggested that the intervening factors of cognitive-behavioral therapy decreases the anxiety of infertile women under the treatment with the IUI assisted reproductive method. The results from Hamid's study (14) also has shown that the cognitive-behavioral intervening factors have caused a significant difference after twelve-month following-up in decreasing the anxiety in infertile women compared with the control group. In addition, these findings are in harmony with the results from the present study.

The analysis of the primary data reveals the fact that the average score of the anxiety and depression of the participants in this study has been moderate. The severity of the anxiety and depression can be one of the most important elements affecting the degree of the effectiveness of the intervening factors of reality therapy; in addition, the studies show that the severity of the disease has a direct relationship with the degree of anxiety and depression. Therefore, with the increase in the degree of anxiety and depression in patients, the degree of the effectiveness of these intervening factors will possibly increase (Zorzon et al., 36; Walling et al., 37). The duration of the disease is also one of the factors that can have a direct effect on the effectiveness of the intervening factors of reality therapy on the decrease of anxiety and depression. The average course of the disease in samples of the present study was around five years (Walling et al., 37).

Since mood and anxiety disorders in infertile women are very common, and according to the studies in this field, it is needed to pay attention to this point that infertile women who utilize the psychological consulting techniques consider some behaviors for reconstructing and solving their issues; therefore, their anxiety and depression are decreased.

It has been revealed that worried infertile women show bias in their memory and attention and they have specific schemas for threat and danger which is related to their real experiences and previous life events. According to aforementioned explanations, it can be stated that cognitive processes, including the process of the schemas and attentional bias along with the suitable stimuli from the outside world are inseparable parts of the anxiety which at least play an important role in the degree and continuation of the anxiety. These findings are in harmony with the idea that in worried people, the data and the stimuli are processed selectively (Beadle and Turner, 38). The simplest explanation is to accept that the process of the threat symptoms is performed unconsciously or subconsciously. Finally, the last explanation is that worried infertile women direct their attention toward those natural stimuli which are related to their emotional concerns; however, this does not necessarily mean that they receive more of these stimuli. In fact, although anxiety leads to the attention bias toward the threatening stimuli, it can disrupt the later active process of them. Actually, reality therapy for worried patients is considered a kind of cognitive reconstruction and help them to encounter the life 
realities and responsibilities and accept them. Therefore, their negative processes, schemas processes, and attention bias decrease (Barlow and Heimberg, 39).

It is believed that in reality therapy approach, anxiety controlling strategies may act due to the negative selfevaluations after an irresponsible behavior. On the other hand, since environmental events and living conditions of a person are effective in shaping up the unconscious unhealthy anxious thoughts, utilizing the behavioral strategies are also considered useful and suitable based on reality therapy attitude (Matthew page35).

On the other side, it is believed that high anxiety disturbs the performance and causes the person not to be able to make a healthy relationship with others and not to accept any responsibilities for them. In reality therapy, it is assumed that lack of behavior evaluation and modification of incorrect cases cause the person's basic needs, including the feeling of being valued and friendship not to be satisfied and causes the person to get worried and stressed. Furthermore, the irresponsible behavior of people leads to anxiety rather than anxiety leads to the irresponsibility of the person. Since the focus on the responsibility aspect and responsible behavior is the main core of the psychotherapy with reality therapy, reality therapy can be effective in learning the responsible behaviors and thus prevent the anxiety in the person. In addition, dealing with the problems in groups helps the person to face the problems more easily and realizes that s/he is not the only person who is dealing with such a problem. Moreover, the member of the group share their experiences and attitudes with each other and through these interactions, they can reach a correct understanding of themselves in different aspects and finally accept their responsible behavior and practice it (Peterson, 40).

It is possibly can be said that one of the reasons of the effectiveness of the group treatment for reality therapy is their educational foundation because in these methods, both behavioral and cognitive aspects are emphasized. In this approach, first, people's recognition of their tasks and responsibilities are changed, then they are taught the cognitive and behavioral treatments in order to be able to experience both the new cognition and behavior simultaneously. In addition, the defects of social skills and socially-accepted values may be the cause of anxiety in infertile women; therefore, reality therapy treatments in applying the above-mentioned skills in other situations of the real life are extended to other behaviors to some extent and as a result, lead to the decrease of anxiety (Beadle and Turner, 38).

\section{Suggestions}

1. According to the results of this study and the effectiveness of reality therapy on the anxiety of infertile women under the treatment with the IUI assisted reproductive method, it is suggested that this medical approach is utilized for infertility treatment in infertility clinics in order to decrease the anxiety of the infertile women who refer to these clinics in order to help them to continue the rest of the treatments and improve the life quality of this group.

2. This treatment have to be tested in the success of the other assisted reproductive method

\section{Limitations}

The small sample, the effect of pre-test, the absence of some of the participants in some treatment sessions, not considering the educational grades, time limitations of the study, lack of accurate instrumentation, lack of in-treatment evaluations, and following-up have been among the limitations of this study.

\section{Appreciation}

In the end, we express our deep gratitude toward Doctor M. Mansouri, head of the Mashhad Novin Infertility Center, Mr. Vaziri, the manager of the center, as well as all the distinguished staff of this center who helped us in this study.

\section{References}

Mohammadi M, KHalajabadiFarahani F. Emotional and psychological problems associated with infertility and coping strategies. Medical Journal of Reproduction and Infertility 2000; 5(1): 22-39.

Heydari P, Latifnezhad R, Sahebi A, Jahaniyan M, Mazlum S. The effect of cognitive behavior therapy on anxiety in infertile women treated with IUI. Medical Journal of Reproduction and Infertility 2001; 40-51.

Sadock BJ, Kaplan HI, Sadock VA. Kaplan \&Sadock's synopsis of psychiatry.Philadelphia: Lippincott Williams \& Wilkins. 2003.

Farahani M. Psychological aspects of coping and coping with infertility and the role of the psychologist.Journal of Fertility and Infertility 2001; 52-59.

FaalKalkgooran L, Bahrami H, Farokhi N, Zeraati H, Tarahomi M. Comparison of anxiety, depression and marital satisfaction in two 
selected groups of fertile and infertile women in Tehran.Journal of Fertility and Infertility 2011; 2: 157-163.

Gibson DM, Myers JE. Gender and infertility: A relational approach on counseling women. Journal ofCounsDev 2000; 78(4): 400-410.

KHodakarami N, Hashemi S, Sedigh S, Hamdiye M, Taheripanah R. Lived experience with infertility. Journal of Fertility and Infertility 2006; 10(4): 287-297.

Behdani F, Moosavi far N, Hobrani P, Soltanifar A, Mohamadnejad M. Evaluation ofanxiety and mooddisordersin infertile womenattendinginfertilityclinic MontaserieMashhad. IranianJournalof Obstetrics and Gynecologyand Infertility 2005; 3 (11):15-23.

GHaraee V, Mazaheri M, Sahebi A, Peyvandi S, Aghahoseini M. The role of cognitive behavioral training on reducing anxiety in women with primary infertility treated by GIFT and ZIFT.Journal of Fertility and Infertility 2004; 170-180.

Choobforooshzadeh A, Kalantari M, Molavi H. Effectiveness of cognitive behavioral stress management on quality of life of infertile women.Iranian Journalof Obstetrics and Gynecologyand Infertility 2010; 3: 17-21.

Ellen A, Marry C, Bostwick Michael J. Efficacy of brief couples support groups developed to manage the stress of in vitro fertilization treatment. Mayo ClinProc 2002; 77: 1060-1066.

Terzioglu F. Investigation into effectiveness of counseling on assisted reproductive techniques in Turkey. JournalPsychosomObstetGynaecol 2001; 22(3): 133-141.

Newton CR, Hearn MT, Yuzpe AA, Houle M. Motives for parenthood and response to failed in vitro fertilization: implications for counseling. JournalAssist Reprod Genet 1992; 9(1): 24-31.

Hamid N. Effectiveness of stress management on depression and anxiety and Infertility. Journal of Behavioral Sciences 2010; 5(1): 5560.

Sedighi R, Daneshkajoori M, Jafarpoor M, HoseiniF,Farimani M. Preparation effects on anxiety and success of treatment in infertile women. Iranian Journal of Nursing 2004; 39: 50-56.

ShoaKazemi M, JafariHerandi M. Comparison ofsingle and marriedstudents' attitudetowards therealityofmarriagefrom the perspective ofGlaser. Journalof SocialResearch 2009; 4: 121-126.

Navvabinezhad SH. Theories of Counseling and Psychotherapy Group. Tehran: Samt Pablication;2008.

Glaser W. Reality therapy. Tehran: khojastePablication; 2000.

Prenzlau S. Using Reality Therapy to Reduce PTSD-Related Symptoms. International journal of reality therapy 2006; 25(2): 23-29.

Loyd BD. The effectiveness of reality therapy/choice theory principles on high school students perception of needs satisfaction and behavioral change. International Journal of Reality Therapy 2005; 1: 5-9.

Kim JU. The effect of a R/T Group counseling program on the internet addiction and self-esteem of internet addiction university students. International Journal of Reality Therapy 2008; 2(20): 4-12.

Peterson AV, change C, Collins PL. The effects of reality therapy and choice theory training on self-concept among Taiwanese university students.International Journal for the Advancement of Counseling 1998; 20: 79-83.

Pasha GH, Amini S. Effect io expectancy and anxious wives of martyrs. New finding in the Journal of Psychology 2008; 37-51.

Ghafari F, Ghanbari B, AghamohamadiyanSherbaf H. Compare the effectiveness of group psychotherapy based on motivational theory and systemayic treatment of marital satisfaction. Psychology and Educational Studies Ferdowsi University 2008; 65-76.

Farahbakhsh K, GhanbariHashemAbadi B. Review the effectiveness of Glaser Couples therapy to reduce stressand increase intimate relationships after thetraumacaused by theperceivedbetrayal. FerdowsiUniversityJournal 2006; 7(2): 174-189.

MoradiShahrbabak F, GhanbariHashemAbadi B, AghaMohamadiyanSherbaf H. Reviewtheeffectiveness ofgrouptherapyonselfesteemlevelsof MashhadUniversity.Educational Study and Psychology 2009; 11( 2): 227-238.

Aghaee A. Effects ofrealitytherapyand mental healthandhope toincrease thefertilityrate ofwomen inoocyte donation. Dissertation.Khoorasgan unit (PhD): Islamic Azad; 2008.

Mashayekhi K. Reviewtheeffectiveness ofgrouptherapyonthelonelywivesof martyrs, in Ahvaz city. Dissertation. Science and Research Branchof Khuzestan(MI): Islamic Azad University; 2008.

Poormohsenikaloori F, Allahyari A. Effectiveness ofempowermentprogramsonmaritalsatisfaction incouples. Journalof ClinicalPsychology 2009; 3(1).

Hoseinpoor M, Darvishi T, Soodani M. The effect ofteachingresponsibilitiesbased on Glasermodelidentity crisisintheAhvazhigh schoolgirls. Newfindingsinpsychologyjournals 2009; 97-106.

Mahram, B. The norming of Schpilberger state-trait anxiety test in Mashhad. M. A. thesis. Psychology and Educational Sciences Faculty, Mashhad Ferdowsi University.1372.

Behdani F, Sargolzaee M, HGorbani E. Study oflifeassociatedwith depressionandanxiety instudentsof Sabzevar. Asrar-Journal of Sabzevar School of Medical Sciences 2000; 7(2): 17-28.

Roohi GH, Rahmani H, Abdolahi A, Mahmoodi GH.Effect of music on anxiety and some physiological variables of patients before abdominal surgery.Journal of Gorgan University of Medical Sciences 2004; 7(1): 75- 78.

Do mar A, Clapp D, Slawsby E, KessedB, Orar J, Freizinger M. The impact of group psychological intervention on distress in infertile women.Journal of Health Psychol 2000; 19(9): 568-575.

Matthew P, Page A. The role of presence in reality therapy.Journal of Anxiety Disorder 2006; 21(5): 742- 751.

Zorzon M, Masi R, Nasuelli D, Ukmar M, Muselli RP,Cazzato G, et al. Depression and anxiety in patients before abdominal surgery. A clinical study in 95 subject. Journal of Neurology 2001; 284(5): 416-442.

Walling MT, Wilkin JA, Kane R. Cognitive dysfunction in infertile women treated with IUI: Assessment, imaging, and risk factor. Journal of Rehabilitation Research \& Development 2006; 43(1): 63-72.

Turner SM, \& Beadle DC. Treating obsessive-compulsive disorder , 2004. New York : Pergamum Press, Inc. 
Heimberg RG, Barlow , DH. New developments In Cognitive-Behavioral therapy For Social Phobia.Journal of ClinicalPsychiatry 2001; 52(): 21-30.

Peterson AV, Chang C, Collins PL. The effect of RT and CT training on self concept among Taiwanese university student. International Journal for the advancement of counseling 2006; vol 20(1): 79-83. 


\title{
Surveying the Effectiveness of Dialectical Behavioral Therapy on Clinical Symptoms, Body Image, Self-Efficacy of People with Bulimia Disorder
}

\author{
FayyazSaberi Mohammad Hassan \\ B.A. in Clinical Psychology, Department of Psychological Sciences, Faculty of Humanities, Neyshabur Branch, \\ Islamic Azad University, Neyshabur, Iran \\ Email: Fsaberi@gmail.com \\ Toozandehjani Hassan* \\ Assistant Professor of psychology, Department of Psychological Sciences, Faculty of Humanities, Neyshabur Branch, \\ Islamic Azad University, Neyshabur, Iran \\ *Corresponding Author Email: H.Toozandehjani@ymail.com
}

\author{
Doi:10.5901/mjss.2016.v7n3s3p136
}

\begin{abstract}
This research is a semi-experimental research (pretest-posttest with control group) with the purpose of surveying the effectiveness of Dialectical Behavioral Therapy (DBT) on clinical symptoms, self-efficacy and body image of people with bulimia disorder. Statistical population of this study was women with bulimia disorder referred to nutrition clinics in Mashhad. The statistical sample of this research was 40 women with bulimia disorder chosen randomly by convenience sampling method and divided into two groups (20 women in experimental group and 20 women in control group), randomly. Applied tools were clinical symptoms questionnaire made by researcher, Sherer self-efficacy questionnaire and PSDQ (Physical Self-Description Questionnaire). For experimental group, Dialectical Behavior Therapy training sessions were held during 12 sessions, 75 minutes per session. During this time, control group didn't get any intervention. After the 12th session, research tools performed on subjects again, as posttest. The data of questionnaires were analyzed by descriptive statistic methods of mean and standard deviation, and Inferential statistics of covariance analysis. The results showed that the clinical symptoms of experimental group were decreased comparing to control group, and self-efficacy and self-descriptin were increased.
\end{abstract}

Keywords: Dialectical Behavioural Therapy, clinical symptoms, self-efficacy, body image, bulimia

\section{Introduction}

Eating disorders are syndromes in which cognitive changes related to food, body weight and bad-eating habits can cause threatening effects to life according to nutrition and medicin. Three types of eating disorders have been identified, including anorexia, bulimia and disorders with no special category (Stang J. ..Story M.). These disorders are shown in allsocial and economical categories and all nations (Muise A, Stein D, Arbess G). Eating disorder is the rifest psychiatric problem among young women and it causes a big number of death.

Eating disorder is identified, based on severe turmoil in eating behavior, and usually it is diagnosed in infancy or early childhood for the first time; like pica, ruminating disorder and infancy nutrition disorder that are placed in "feeding and eating disorders in infancy or childhood" part (Lindzy, Pavel; quoted from Yans and Nikkhoo, 2000).

Bulimia is rifer than anorexia, and its prevalence estimation is between 2 to 4 percent among young women. Its prevalence rate among women is 10 times much than men, but its start age at adolescence is later that start age of anorexia. Bulimia comparing to anorexia, causes less numbers of death, and its comparative or complete improvement rate is higher. The prevalence rate of this disorder in industrial countries is almost $1 \%$ of general population (Kaplan and Sadock's.2007. quoted from Rezaee). Bulimia is a mental disorder that is identified by eating a big amount of food in a short time and then purifying extra calories by vomiting or other extremist actions (Halgin RP, Whitborne SK, 2002).

According to DSM V, the main criteria for bulimia are: overeating periods that their frequency are rather high (at least once per week) and they last at least 3 months; Following compensatory behaviors in order to avoiding weight increasing, generally vomiting, bad consumption of laxatives, diuretics or vomiting drugs (10\%).

In 20\% cases, patientsturn into excessive exercises or strict diets as compensatory behavior; body weight is not as less as anorexia; patient has fear of being obese; he tends to lose weight continuously; self-valuation highly related to the 
shape and weight of body.

A lot of factors have role in bulimia, like clinical symptoms, self-efficacy and body image. People with bulimia suffering from weak self-esteem, disability feeling, inefficacy, lack of control on life, perfectionism, anxiety, depression, and anger. They show high-level of impulsiveness and negative image of their body (McCabe, M. P.,\& Vincent, M. A., 2003)

Evidences show that anxiety and depression in people with bulimia who are after clinical helps, are more, comparing to ordinary samples of population. Clinical symptoms with comorbidity with obesity in these people, like psychosis symptoms, body-dysmorphic disorder, major depression, suicidal tendency and eating disorders, are shown (Groth-Marnat, 1997).

Women with bulimia disorder, are more susceptible to anxiety and depression and other psycho-pathological symptoms, rather than men suffering from bulimia. Some researches have shown that prevalence of mental disorders like depression, anxiety disorders and binge eating disorder in people with bulimia are significantly higher comparing to ordinary people. Anyhow, it is not clear whether this comorbidity of mental disorders and obesity is because of a common reason or bulimia and metabolism disorders, have mental side effects and vice versa. Fairburn and colleagues (1998) in their studies showed that obese people with bulimia disorder, more likely used to suffer from negative self-valuation, parent's depression, major depression disorder, behavior problems and deliberately self-harming.

Another effective factor on bulimia, is self-efficacy. Self-efficacy is a constructing power that cognitive, social, emotional and behavioral skills are organized by it, to achieve various aims, in an effective way(Bandura, 1997). Selfefficacy believes increase functions of immune system; cause better physical health, flexibility in facing mental pressure, and result better social and mental adaptation. The growth of self-efficacy believes in special fields like job, sport, weight control, quit smoking and alcohol, and mental health problem consequences positive outcomes (Kar, A. 2006).

Body image is another effective factor on bulimia. Body self-concept has effects on the self-valuation feeling experienced in relationships; and it anticipate relationship satisfaction (Trzesniewskiand colleagues , 2009).

The researches made by Brown and colleagues (2009) showed that overweighting has negative effect on body self-concept. Overweight people experience intangible consequents of losing self-esteem, personal problems in social relationships, physical limitation and prejudice of family, friends staff and nurses and even strangers.

In fact, body image or body-self is formed by direct experience of body organs and status, and by social relationships. In social relationships ideals are shown as visible and invisible behaviors, and then get criteria for comparing one's real status with them.

After such comparison, individual feels satisfied or unsatisfied from his body (Bouricinco, translator: Behzad, 1999).Cach and Pruzinsky (2004) stated that face and body fitness assessment, body satisfaction and women's subjective impression are the components of body image that impact on women's dissatisfaction. Huang and colleagues' study (2009) showed that negative body image can cause unwanted social-mental impacts including anorexia or bulimia, depression, social anxiety, sexual dysfunction and reduction of self-confidence.

One of therapy methods that seems to be effective against bulimia, is dialectical behavioral theapy (DBT). This is a cognitive-behavioral therapy that basically is recognized by Marsha M. Linehanas a therapy for people attempting selfharming behaviors.

This cognitive behavioral therapy approach, at first was introduced for treating border line personality disorder (BPD). This approach, has mixed the interventions of CBT (that is based on change principle) with Eastern teachings and techniques (that are based on acceptance principle).According to this, he introduces four intermediary components: core mindfulness and distress tolerance as acceptance components and emotional regulation and interpersonal efficacy as change components (Wagner and colleagues,2007.quoted from Gharavi,2011).

Furthermore, as DBT was presented as a completely structured-therapeutic protocol and therapists could apply it more easily, it caused DBT to be used in a rather vast range of disorders, in addition to borderline personality disorder.

Evidences show that this approach in eating disorders treatment, especially binge eating disorder (Telch, Agras, Linehan, 2001;Feigenbaum, 2007), is effective. Cognitive-behavioral DBT therapy covers both cognitive disorders and behavioral abnormality aspects of people suffering from bulimia.

The purpose of cognitive-behavioral therapy is reducing over eating and purifying behaviors in people with bulimia, and changing their abnormal viewpoint about body shape and weight (Wilson, G.T., Fairburn, 1993). According to this viewpoint, bulimia continues because of disability in facing with unpleasant events, and proceeding inefficient thoughts and feelings about weight and body shape; and this cause overeating and purifying (Wilson, G.T., Fairburn, C. G., Agras, W. S., Walsh, B. T., \& Kraemer, H, 2002).

Researches have shown that DBT increases positive body image in people with bulimia (Telchand colleagues,2001;Vocks S, Wächter A, Wucherer M, Kosfelder J.2008). Furthermore, Denaro's researches (Denaro, J. L. 